\title{
What Is Different in the Population of the Brazilian Amazon Region so that They Have a Low Frequency of KRAS Gene Mutations?
}

\author{
Luis Eduardo W. de Carvalho ${ }^{a, b}$ Jonathan S. Sarraf ${ }^{a, c}$ \\ Ana Carolina M. Oliveira ${ }^{a, d}$ Nilson D.B. Neto ${ }^{a, c}$ Thiago F. Câmara ${ }^{a, d}$ \\ Fernando Luiz A. Fonseca ${ }^{b, e} \quad$ Fernando Adami ${ }^{a, b}$ \\ ${ }^{a}$ Oncologica do Brasil - Ensino e Pesquisa, Belém, Brazil; ${ }^{b}$ Faculdade de Medicina do \\ $A B C$, São André, Santo André, Brazil; 'Universidade Federal do Pará, Belém, Brazil; \\ 'Universidade do Estado do Pará, Belém, Brazil; ' Universidade Federal de São Paulo, \\ São Paulo, Brazil
}

\section{Keywords}

KRAS mutation · Brazilian Amazon · Colorectal cancer

\begin{abstract}
Background: Colorectal cancer $(\mathrm{CRC})$ has been described in the medical literature as resulting from many forms of interaction between lifestyle, genetics, and geographical origin. Genetically, the KRAS gene has a negative impact on the general survival and prognosis of patients when mutated. Methods: This study was conducted in Brazil and included information about 60 patients with CRC stage III and IV examined at the Day Hospital Oncológica do Brasil, whose DNA was analyzed with the PCR-DNA method to determine the existence of a KRAS mutation. Results: The results revealed that $18.3 \%$ of the individuals analyzed showed a KRAS mutation ( $24 \%$ of mutations were found in men and $14.3 \%$ in women), which is a smaller proportion than those found in other large studies across the globe. Conclusion: As
\end{abstract}




\section{Case Reports in Oncology}

our analysis is one of the very first published about this topic, more studies are necessary to understand the role of KRAS mutations and the associated variables in populations such as that of the Amazon region.

(C) 2017 The Author(s)

Published by S. Karger AG, Basel

\section{Introduction}

It is well known that factors such as genetics, lifestyle [1, 2], and geographical origin [3] contribute to the development of many types of cancer, including colorectal cancer (CRC). This means that the disease itself is a result of complex interactions between genes and the environment.

Genes such as Kirsten ras sarcoma (KRAS), located on chromosome 6, play a very important role in this neoplasia. The mutation of this gene unfavorably influences the targeted therapy treatment in patients with metastatic CRC, producing negative consequences, such as increased risk of recurrence, lower disease-free survival, and lower overall survival [3-5].

According to the latest studies, around $40 \%$ of the patients with metastatic CRC have KRAS gene mutations [4]. However, this rate may present singularities according to the studied population [3]. Thus, this study aims to characterize the rate of a mutated KRAS gene in patients with CRC (III/IV stages) in a sample from Belém in the Brazilian Amazon region with specific characteristics, including environmental exposures, population history of indigenous miscegenation, and unique sociocultural aspects [6].

\section{Materials and Methods}

This descriptive study was conducted from January 2009 to October 2015 at the Day Hospital Oncológica do Brasil. Inclusion criteria and study patients were the following: all patients with CRC stages III and IV were examined to assess mutations in the KRAS gene. Patients with incomplete or inconsistent medical records were excluded.

Data were collected from the medical records. Information about the status of KRAS gene mutations was obtained by tumor biopsy. The samples were fixed in paraffin and analyzed for mutations, specifically in codons 12 and 13 of chromosome 6 . The evaluation of mutations was carried out by the PCR-DNA method, followed by automatic sequencing and gene sequence analysis. All evaluations were performed in a single central laboratory using the same criteria.

Data collection was conducted by pairs of researchers, who extracted data in isolation and independently according to the same criteria, and after extraction, a data consistency evaluation was performed. If there was disagreement between the researchers, the medical records would be re-evaluated by the same researchers independently and then compared again. If they still disagreed, a third researcher would be consulted for final evaluation.

A binomial test was performed to evaluate the KRAS gene mutation proportions. The Fisher exact test was done to analyze the association of KRAS gene mutation status with sex and age group. The association was statistically significant if $p$ values were $<0.05$. The statistical program used was Stata 12.0. 


\section{Case Reports in Oncology}

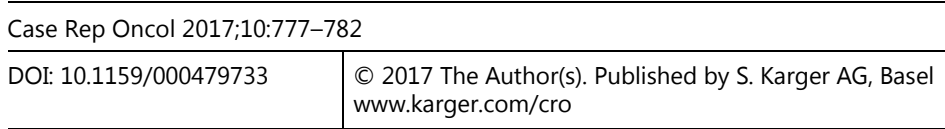

de Carvalho et al.: What Is Different in the Population of the Brazilian Amazon Region so that They Have a Low Frequency of KRAS Gene Mutations?

\section{Results}

In this study, the average age of the 60 subjects was 63.4 years (standard deviation $=$ 15). There was a low proportion of individuals with a mutation of the KRAS gene $(n=11$, $18.3 \%, p<0.001)$. The proportion of those with a mutation in men and women was 24 and $14.3 \%$ ( $p=0.500$ ), respectively. Besides, the proportion of those with a mutation in the evaluated age groups was $37.5 \%$ (27-48 years old), 19.4\% (49-69 years old), and 11.1\% (70-90 years old) ( $p=0.301)$. The calculation of the statistical power to identify this association, made a posteriori, indicated a test power of $90.1 \%$.

\section{Discussion}

There are no records of studies assessing the proportion of those with a mutation in the KRAS gene in the Brazilian population, let alone in a specific population of the Amazon region, as attempted in this article. The proportion of KRAS mutations varies in different countries between 27 and 47\% [3-5, 7-12]. In our study, a smaller proportion of mutations in the KRAS gene (18.3\%) was found compared with other large studies [3-5, 7-12] (Fig. 1).

The variation in the proportion of the mutated KRAS gene, as well as in other genes from the RAS family, such as the NRAS gene, is still widely debated. A study suggests that the geographical origin of each population influences this proportion [3]. However, large studies, like RASCAL I and II which evaluated 13 and 21 countries, respectively, totaling over 5,000 individuals, showed no significant differences between the proportions of mutations in the studied populations [4, 7]. These 2 studies, though evaluating numerous countries, have limitations because they do not include the South American countries, like Brazil. This country has regions with specific characteristics, such as the Amazon, with environmental exposures, population history of indigenous miscegenation, and unique sociocultural aspects [6] that can lead to variations in the proportion of mutations in the KRAS gene.

Other factors that could be related to mutations in the KRAS gene, such as gender and age, were evaluated in other studies, but no association was found between these variables and the proportion of mutations $[7,8,11]$ as also shown in our data (Table 1). Beyond genetic factors, recent studies have been suggesting a possible association between alimentation, such as a high ingestion of lipids, and a high proportion of CRC-related mutations [12].

The sample was composed of 60 subjects treated at the Oncology Center of Belém and was evaluated by a single laboratory. This standardization in the KRAS gene mutation evaluation minimizes the possibility of errors related to the type of test and parameters used in the verification of this mutation, which are factors that were pointed out as potential problems in large studies $[4,7]$. Besides, we highlight that the power of this study was able to reach $90 \%$ even with such a small sample.

\section{Conclusion}

Our study illustrated that it was possible to observe a difference from the proportion of KRAS gene mutations found in other papers published around the world. As this was the first 
study to detect possible differences between determinant variables for mutations of the KRAS gene in CRC, more studies are necessary to understand the role of KRAS mutations and the associated variables in populations still poorly or not studied, such as the Amazonian population.

\section{Acknowledgments}

We are grateful for the support received by the Oncologica do Brasil - Ensino e Pesquisa, which provided us with the space, material, and financial support necessary to conduct this study.

\section{Statement of Ethics}

In this study, informed consent was not necessary according to Resolution 466/12 of the National Health Council, and it was delimited by the Ethics Committee responsible for this research. The study was approved by the Ethics Committee designated by the Platform Brazil with protocol No. 1.412.975.

\section{Disclosure Statement}

This research received no specific grant from any funding agency in the public, commercial, or not-for-profit sectors. The authors declare no conflicts of interest.

\section{References}

1 Gonzalez CA, Riboli E: Diet and cancer prevention: contributions from the European Prospective Investigation into Cancer and Nutrition (EPIC) study. Eur J Cancer 2010;46:2555-2562.

-2 Migliore L, Migheli F, Spisni R, et al: Genetics, cytogenetics, and epigenetics of colorectal cancer. J Biomed Biotechnol 2011;2011:792362.

-3 Bader T, Ismail A: Higher prevalence of KRAS mutations in colorectal cancer in Saudi Arabia: propensity for lung metastasis. Alexandria J Med 2014;50:203-209.

-4 Andreyev H, Norman A, Cunningham D, et al: Kirsten ras mutations in patients with colorectal cancer: the "RASCAL II" study. Br J Cancer 2001;85:692-696.

5 Lièvre A, Bachet J-B, Boige V, et al: KRAS mutations as an independent prognostic factor in patients with advanced colorectal cancer treated with cetuximab. J Clin Oncol 2008;26:374-379.

6 Resende ALS, Mattos IE, Koifman S: Dieta e câncer gástrico: aspectos históricos associados ao padrão de consumo alimentar no Estado do Pará. Rev Nutr 2006;19:511-519.

7 Andreyev HJN, Norman AR, Clarke PA, et al: Kirsten ras mutations in patients with colorectal cancer: the multicenter "RASCAL" study. J Natl Cancer Inst 1998;90:675-684.

-8 Bando H, Yoshino T, Yuki S, et al: Clinical outcome of Japanese metastatic colorectal cancer patients harbouring the KRAS p.G13D mutation treated with cetuximab + irinotecan. Jpn J Clin Oncol 2012;42:1146-1151.

-9 Calistri D, Rengucci C, Seymour I, et al: Mutation analysis of p53, K-ras, and BRAF genes in colorectal cancer progression. J Cell Physiol 2005;204:484-488. 


\section{Case Reports in Oncology}

\begin{tabular}{l|l} 
Case Rep Oncol 2017;10:777-782 \\
\hline DOI: $10.1159 / 000479733$ & $\begin{array}{l}\text { (C) } 2017 \text { The Author(s). Published by S. Karger AG, Basel } \\
\text { www.karger.com/cro }\end{array}$
\end{tabular}

de Carvalho et al.: What Is Different in the Population of the Brazilian Amazon Region so that They Have a Low Frequency of KRAS Gene Mutations?

10 Di Fiore F, Blanchard F, Charbonnier F, et al: Clinical relevance of KRAS mutation detection in metastatic colorectal cancer treated by cetuximab plus chemotherapy. Br J Cancer 2007;96:1166-1169.

11 Gajate P, Sastre J, Bando I, et al: Influence of KRAS p.G13D mutation in patients with metastatic colorectal cancer treated with cetuximab. Clin Colorectal Cancer 2012;11:291-296.

-12 Inamura K, Song M, Jung S, et al: Prediagnosis plasma adiponectin in relation to colorectal cancer risk according to KRAS mutation status. J Natl Cancer Inst 2016;108:djv363.

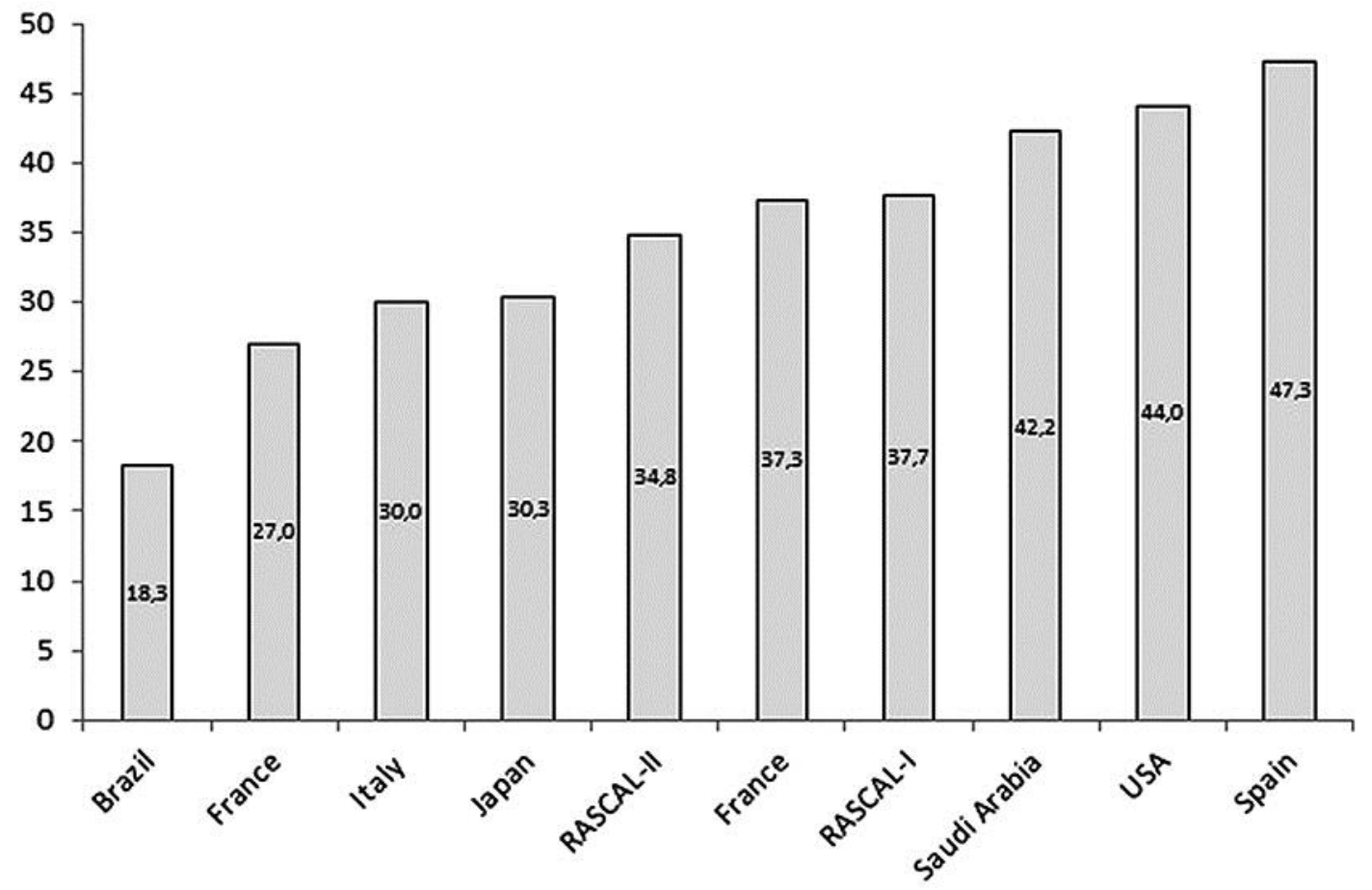

Fig. 1. Proportion of KRAS gene mutations. 


\section{Case Reports in Oncology}

de Carvalho et al.: What Is Different in the Population of the Brazilian Amazon Region so that They Have a Low Frequency of KRAS Gene Mutations?

Table 1. Proportion of the mutated KRAS gene according to country, year of publication, and number of subjects assessed

\begin{tabular}{|c|c|c|c|c|}
\hline Authors [ref.] & Country & Year & Subjects, $n$ & Sample description \\
\hline Lièvre et al. [5] & France & 2008 & 89 & $\begin{array}{l}\text { Metastatic colorectal patients }(n=89) \text {; males = } \\
44 \text { and females = 45; from } 6 \text { centers in France } \\
\text { (Groupe Hospitalier Universitaire-West Paris, } \\
\text { Groupe Hospitalier Universitaire-East Paris, } \\
\text { Gustave-Roussy Institute, Clermont-Ferrand } \\
\text { Hospital, Val d'Aurelle Institute, and Reims } \\
\text { Hospital); mean age = } 59.2 \text { years }\end{array}$ \\
\hline
\end{tabular}

\begin{tabular}{lllll}
\hline Calistri et al. [9] & Italy & 2005 & 100 & $\begin{array}{l}\text { Tissue samples of colorectal cancer patients }(n= \\
\text { 100) from Forlì and Rimini Hospitals in Italy }\end{array}$ \\
\hline Bando et al. [8] & Japan & 2012 & 109 & $\begin{array}{l}\text { Colorectal cancer patients }(n=109) \text { from } 9 \\
\text { institutions in Japan; males }=65 \text { and females }= \\
\end{array}$ \\
& & & $\begin{array}{l}44 ; \text { median age with KRAS mutation }=66.73 \\
\text { years }\end{array}$
\end{tabular}

Andreyev et al. [4] 21 countries $2001 \quad 3,439 \quad$ Metastatic colorectal cancer $(n=3,439)$ patients
(RASCAL II) from 35 centers in 19 countries; male $=1,824$ and female $=1,611$; median age male $=67$ years and median age female $=69$ years

\begin{tabular}{llll}
\hline Di Fiore et al. [10] & France & 2007 & 59 \\
\hline Andreyev et al. [7] & $\begin{array}{l}\text { 13 countries } \\
\text { (RASCAL I) }\end{array}$ & 1998 & 2,721 \\
& & &
\end{tabular}

Chemotherapy-refractory metastatic colorectal cancer ( $n=59$ patients)

European researchers who had previously published reports on colorectal cancer patients $(n=1,550)$ from Singapore, Japan, and Australia contributed 374 patients ( $23 \%$ of Australia's and Southeast Asia's published total); male $=1,455$ and female $=1,238$; median age male $=67$ years and median age female $=69$ years

Bader et al. [3] $\quad$ Saudi Arabia $2014 \quad 83 \quad$ Metastatic colorectal cancer $(n=83)$ from a single center in Saudi Arabia; males $=48$ and females $=35$; median age $=55$ years

Inamura et al. [12] USA $\quad 2016 \quad 307$

Colorectal cancer patients $(n=307)$ from the Nurses' Health Study; mean age male $=66.2$ years and mean age female $=58$ years

Gajate et al. [11] $\quad$ Spain $\quad 2012 \quad 110$

Colorectal cancer patients $(n=110)$ from Hospital Clínico, San Carlos; male = 59 and female $=51$; median age with KRAS mutation = 66.73 years 